Research Article

Journal of Extension Education

Vol. 32 No. 4, 2020

DOI:https://doi.org/10.26725/JEE.2020.4.32.6595-6603

\title{
Influence of Agricultural Financing Awareness on Financial Problems of Agricultural Entrepreneurs
}

\author{
Purnima Newar* and Anjan Bhuyan*
}

\begin{abstract}
Agribusiness is characterized by uncertain returns and thus it confronts the agricultural entrepreneurs with various situations that impede their capital requirement. This paper attempts to understand the financial problems of agricultural entrepreneurs and to make a relational analysis of their awareness of agricultural financing with their financial problems. The study was conducted in Assam, situated in the northeastern part of India. Multi-stage sampling was used to reach 96 agricultural entrepreneurs. It was found that the inadequate savings and cumbersome process in applying for a loan were the major causes of financial problems of agricultural entrepreneurs and $64 \%$ of agricultural entrepreneurs have medium level of awareness on agricultural financing. Analysing the influence of agricultural financing awareness of agricultural entrepreneurs on their financial problems it is concluded that with the increase in the agricultural financing awareness level of agricultural entrepreneurs their financial problems can be reduced to a great extent.
\end{abstract}

Keywords: Agricultural entrepreneurs; Agricultural financing awareness; Financial problems; Assam; India.

\section{INTRODUCTION}

The agricultural sector shares a dominant position in the upliftment of the rural economy of Assam which is situated in the northeastern part of India. 99\% of the total landmass of Assam comes under rural area and nearly $50 \%$ of the overall land area is employed for farming (Sharma, 2012). Therefore, agriculture plays an imperative role in the socio-economic growth of the state by creating livelihood for a major portion of the population (Yadav, 2013). These days, practising agriculture is not only limited to a means of survival but become a source of livelihood and taking the direction of entrepreneurial activity. Such potency leads to the creation of agricultural entrepreneurs which is defined by Chander (2016) as creative farmers who are innovating and applying suitable technologies and practices developed by them or integrating into their farms the technologies developed elsewhere.

\footnotetext{
*Department of Business Administration, Tezpur University, Assam, India
}

Received : 23-06-2021; Accepted : 18-08-2021 
But the major aspect is that such activities demand a significant amount of capital that needs to be invested. Besides their saving, they often have to rely on the outside source for acquiring funds. Nath et al. (2016) found that lack of capital and unavailability of timely credit facilities act as major constraints for future improvement of agricultural activities. Shanmugavadivel (2015) stated that credit facility enables the farmer to attain the required capital for increasing agricultural production and it can boost other factors of production by making the latent or underused capacities, functional. Thus, agricultural financing performs a crucial role in the advancement of the agricultural sector (Ajayi et al. 2017). Daily agricultural life depends on the sustainability of the financial power, which is influenced by the information chain of the financial providers (Ulusoy, 2019). Several policy measures have been introduced by the government to boost up the accessibility of farmers towards the institutional sources of credit (Subramaniam and Shivananjappa, 2017). The umbrella coverage of agricultural financing services from banks allows the agricultural entrepreneurs to carry out their farming process in a smooth way. There are various schemes in India through which the agricultural loan is provided at a subsidized rate. Besides that, with the introduction of the Kisan Credit Card (KCC), agricultural loans are provided for consumption purposes, postharvesting expenses, marketing expenses, the loan with crop insurance and the agricultural entrepreneurs also get the option for social security schemes and loans on warehouse receipt. It also gives the provision for the
Ioan without collateral security. Availing such facilities require awareness among the agricultural entrepreneurs. However, inadequate awareness of formal agricultural financial services would drive the agricultural entrepreneurs to the doorstep of the unorganized sector (Shanmugavadivel, 2015). Widhiyanto et al. (2018) were concerned that better awareness creates more access to financial institution's products and services. However, reviewing the prior research papers, we found a gap in correlating the awareness on agricultural financing with financial problems of agricultural entrepreneurs. Therefore, this study has attempted to fulfil the following objectives with the motive that understanding financial problems of agricultural entrepreneurs give insight into the major reasons that impede their capital requirement and answer whether the awareness of agricultural financing affects the financial problems of the agricultural entrepreneurs:

- To identify the financial problems of agricultural entrepreneurs.

- To determine the level of agricultural financing awareness of agricultural entrepreneurs.

- To determine the effect of awareness on agricultural financing on the financial problem of agricultural entrepreneurs.

\section{METHODOLOGY}

The research design of the paper is descriptive followed by a cross-sectional study. The study was conducted in Assam from January 2021 to April 2021. In this study, only those agricultural entrepreneurs were 
taken into consideration who produced for commercial purpose, come within the purview of the agriculture and horticulture sector and engaged in the business for at least 2 years. Since there was no record or list of the total population of agricultural entrepreneurs in the study area, the population was considered as infinite in this paper and from each district, the samples of agricultural entrepreneurs were selected with the help of agricultural extension officials assigned by the respective district agriculture office. Accordingly, 96 samples were selected considering the minimum number of samples that needed to be present as per the number of variables in the study, use of survey scale and to run the statistical test such as t-test, ANOVA (Delice, 2010; Louanglath, 2017; Cohen et al., 2005). Multi-stage sampling was used. Assam has 6 agro-climatic zones that are divided into Brahmaputra and Barak Valley. Brahmaputra valley was selected for its wide geographical location and more agricultural production. The valley has four agro-climatic zones and from each zone, one district was selected based on the highest Human Development Index report of 2014. In this way, Nagaon, Lakhimpur, Jorhat and Kamrup (Metro) districts were selected. Information from the respondents was collected with the help of a schedule. The questions in the schedule mainly comprised socio-economic factors, financial problems and their (respondents) awareness of agricultural financing. After conducting the pilot survey, only those items in the final schedule were included which were considered relevant by the 20 branch managers of different banks and 20 agricultural officers and extension assistants of the Agriculture and Horticulture Department of the selected districts of Assam. The data were analyzed with the help of SPSS and MS-Excel. However different techniques were used based on the nature of the objective and its phenomenon.

Based on prior research papers and pilot survey, seven items were considered to measure the causes of financial problems of agricultural entrepreneurs. The items include inadequate savings, less source of borrowing, high risk in borrowing, lack of awareness on applying for bank loan, cumbersome process in applying for bank loan, high rate of interest and lack of collateral security. To quantify the items of financial problems, a 7- point interval rating scale was used where 1 denoted least agree and 7 referred to strongly agree to the causes of the financial problems. Subsequently, the mean score was calculated based on ratings provided by the respondents on different financial problems. The individual mean score of the items was calculated to compare the items causing the financial problem and the overall mean score of the financial problem was ascertained to correlate it with the awareness of agricultural entrepreneurs on agricultural financing.

Theitems that measured the awareness level of the agricultural entrepreneurs on agricultural financing were grouped into five factors that were; awareness of basic banking services, periodicity of loan, collateral security on loan, various agricultural financing schemes and facilities on KCC (Kisan Credit Card). Each 
factor was represented with several items and the questions were asked in the dichotomous form and scores were measured accordingly by segregating the responses into ' 1 ' for 'aware' and ' 0 ' for 'not aware'. The overall scores on the items were then categorised into three different levels i.e. high, medium and low. If the score of the respondents fell below the (Mean-Standard Deviation) the awareness level was taken low. The awareness level was considered medium when the score reclined between (Mean \pm Standard Deviation. If the score was above (Mean + Standard Deviation) the awareness was considered high (Shanmugavadivel, 2015).

Relationship between agricultural financing awareness and financial problems of agricultural entrepreneurs was analyzed using One-Way ANOVA. The independent variable was the level of awareness on agricultural financing and financial problem of the smallscale commercial farmers was the dependent variable. Using this variable, the null hypothesis was constructed as:

There is no significant difference in the mean score of financial problems across the levels of awareness on agricultural financing.

\section{FINDINGS AND DISCUSSION}

\section{Financial problems of Agricultural Entrepreneurs}

The reasons leading to the financial problem of the agricultural entrepreneurs are depicted in Figure 1. The $x$-axis represents the variables of financial problems and the mean score of the variables leading to the financial problem is presented in the $y$-axis.

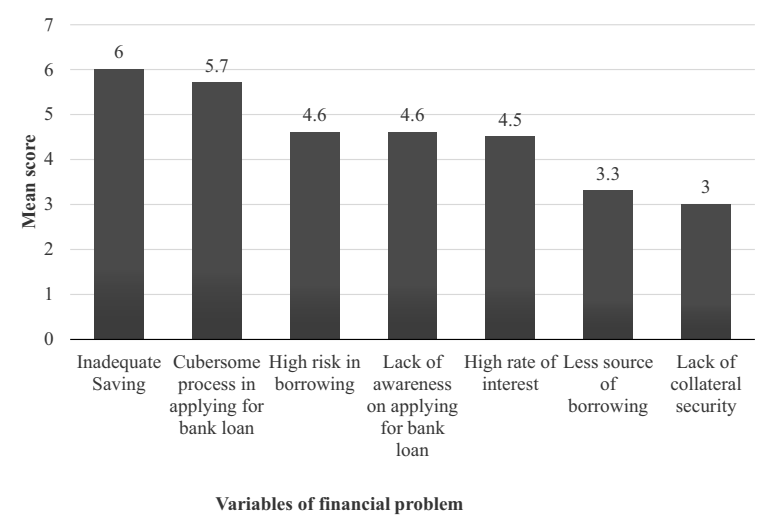

Figure 1: Causes of Financial Problems of Agricultural Entrepreneurs

A high mean score indicates more financial problems for agricultural entrepreneurs. Here, it can be seen that inadequate savings affected mostly to financial/capital requirement of agricultural entrepreneurs which was quite found in prior research papers on the financial-related problems faced by the entrepreneurs (Swathy \& Benazir, 2014; Jayadatta, 2017). However, it can be interpreted from Figure. 1 that the cumbersome process in applying for a bank loan affected the financial requirement with an average rating of 5.7 out of 7 . This result also supports the findings of the study conducted by Gichuki et al., in 2014 where $75.7 \%$ of entrepreneurs rarely apply for loans from banking institutions due to strict terms. There was an almost equal rating on the high risk in borrowing, lack of awareness on applying for a bank loan and high rate of interest.

\section{Awareness level of Agricultural entrepreneurs on Agricultural Financing}

The awareness level of agricultural entrepreneurs was segregated based on the 


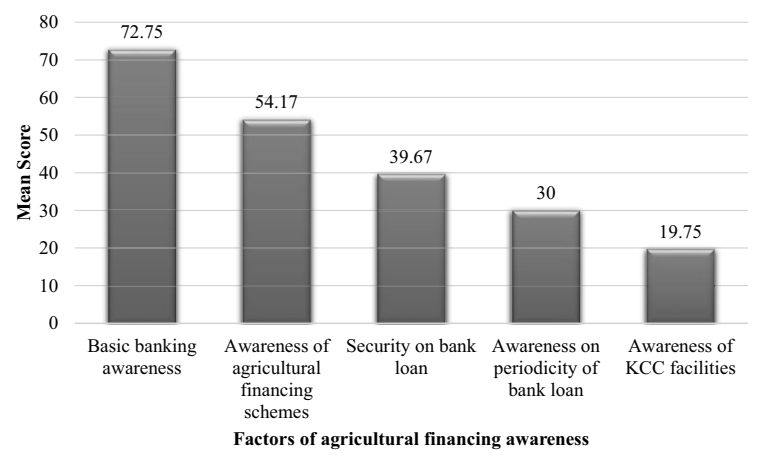

Figure. 2: Dimensions of Agricultural Financing Awareness

overall score of all the factors of agricultural financing awareness. However, to understand in which factors the agricultural entrepreneurs have more or less awareness, a comparative data based on the mean score of the factors of agricultural financing awareness is presented in Figure. 2. The mean score on each factor of agricultural financing awareness was calculated by dividing the total score of the items of each factor by the number of items in each factor.

Comparing the mean scores on awareness of each factor of agricultural financing, it was found that awareness of basic banking services scored the highest (72.75). The items on basic banking services included their awareness on types of deposits, method of charging interest, awareness on ATM card and internet banking service. On the other hand, the mean score on awareness on the security of loan was quite low (39.67). The security of the loan was represented with awareness on loan with mortgage, the loan without collateral security and the maximum amount of loan without collateral security. On analysing the reason behind such mean score on the security of the loan, it was found that out of 96 respondents, only 22 respondents recorded were aware of the loan without collateral security and only one respondent was aware of the maximum amount of loan without collateral security. Among the factors, the mean score on KCC (Kisan Credit Card) facilities was recorded as the lowest (19.75). The awareness of KCC facilities was measured using 8 items and detailed analysis of the items revealed that besides the awareness of the availability of crop loans with the help of KCC; out of 96 respondents, only 29 of them were aware of the availability of loans for agricultural equipment and 33 respondents were aware of the availability of loan for allied activities using KCC. Surprisingly, it was found that none of the respondents was aware of the validity of Kisan Credit Card (KCC), the availability of loans for consumption requirement, marketing of farm produce, post-harvesting expenses and loan on warehouse receipt using Kisan Credit Card (KCC). Similar findings were also highlighted by Mangalam, 2019.

The awareness level of the agricultural entrepreneurs on agricultural financing was determined. and it was found that majority had medium awareness level.

\section{Effect of Agricultural Financing Awareness on Financial Problems of Agricultural Entrepreneurs}

In the process of examining the effect of the level of agricultural financing awareness on the financial problems of agricultural entrepreneurs, a one-way ANOVA was conducted. ANOVA is based on the assumption of the normal distribution thus the test of normality was conducted using the 
Shapiro Wilk test. As mentioned by Ghasemi and Zahediasl (2012) on the excellence of the Shapiro Wilk test over Kolmogorov-Smirnov test and a betterchoice for testing the normality of data. "If the p-value of Shapiro Wilk test is greater than the alpha value (0.05), the data is normal" (Lund Research Ltd., 2018, p. 1). After conducting the Shapiro Wilk test, the result showed the $p$-value 0.113 (greater than 0.05), consequently, the data were assumed to be normally distributed. The data also met the criteria for homogeneity of variance which was tested with the help of Levene's test. The result of Levene's test showed the p-value of 0.164 which was more than 0.05 and indicated the equality of variance among the groups.

Table 1 displays the summary of ANOVA where it showed that $p$-value (Sig.) is $0.000(<0.05)$, therefore the null hypothesis 'there is no significant difference in the mean score of financial problems across the levels of awareness on agricultural financing' was rejected. This inferred that there was a statistically significant difference in the mean score on financial problems of agricultural entrepreneurs having high, medium and low level of awareness on agricultural financing. Table 2 highlights the difference in the average score on the financial problems of agricultural entrepreneurs across the three levels of awareness on agricultural financing. The data from table 2 revealed that the mean score on the financial problem at the low level of awareness was 37.54, at medium level of awareness the mean score reduced to 32.03 and for the respondents with high level of awareness on agricultural financing, the respective mean score on finance problem was further reduced to 26.55 . This indicated that the financial problem of agricultural entrepreneurs decreased with the increase in the level of awareness on agricultural financing. Similar observation was also made by Thakur and Barman (2013).

Table 1.

Summary of ANOVA

\begin{tabular}{|c|c|c|c|c|c|}
\hline Particulars & Sum of squares & df & Mean square & F & Sig. \\
\hline Between groups & 1031.339 & 2 & 515.669 & 8.757 & .000 \\
\hline Within groups & 5476.620 & 93 & 58.888 & & \\
\hline
\end{tabular}

Table 2.

Descriptive table of ANOVA

\begin{tabular}{|c|c|c|}
\hline $\begin{array}{c}\text { Level of awareness on } \\
\text { agricultural financing }\end{array}$ & Number of respondents & $\begin{array}{c}\text { Mean score on financial } \\
\text { problem }\end{array}$ \\
\hline Low & 13 & 37.54 \\
\hline Medium & 61 & 32.03 \\
\hline High & 22 & 26.55 \\
\hline Total & 96 & 31.52 \\
\hline
\end{tabular}


Therefore, it can be concluded that the financial problem of agricultural entrepreneurs is dependent on their level of awareness of agricultural financing and both the variables share a substantial negative relationship with each other.

\section{CONCLUSION}

Empirical analysis from this study has revealed that agricultural entrepreneurs has face several problems that impede the capital requirement in their agri-venture activities. An inadequate saving, cumbersome process on applying for a loan and high risk in borrowing were some of the important causes that add to their financial problems. It was found from the survey that most of the agricultural entrepreneurs had a medium level of awareness on agricultural financing but the level of awareness was mostly affected on account of their awareness of the availability of loans without collateral security, the maximum amount of loan without collateral security, periodicity of loan and the additional facilities that are available with Kisan Credit Card. Analysing the financial problems of agricultural entrepreneurs showed a negative relationship with their awareness of agricultural financing. Thus, the study concludes that more efforts should be made to increase the awareness of agricultural entrepreneurs on agricultural financing to combat their problems relating to capital requirements. Though various steps are taken by the government to increase awareness on agricultural financing which also comes in the form of the financial literacy programme, no such effective impact has been seen at the grassroots level. Therefore, it is suggested that along with the involvement of bank officials there should be active engagement of agricultural extension officials to increase awareness of agricultural financing at the grassroots level.

\section{REFERENCES}

Ajayi, M.A, Nageri, K.I, \& Akolo, C.S. (2017). Impact of agricultural financing policy and deposit money bank loan on agricultural sector productivity in Nigeria. Amity Journal of Agribusiness, 2(1), 1-11.

Chander, M. (2016). Agripreneurs: The emerging role models. Global Forum on Agricultural Research and Innovation (GFAR). Retrieved from https://blog. gfar.net/2016/05/03/agripreneurs theemerging-role-models/

Cohen, L, Mansion, L, \& Morrison, K. (2005). Research Methods in Education. Taylor and Francis e-Library. Retrieved from https://ge3143myd.files.wordpress. com/2011/02/research-method-ineducation-5th-cohen.pdf

Delice, A. (2010). The sampling issues in quantitative research. Educational Sciences: Theory and Practices, 10 (4), 2001-2018. Retrieved from https://files.eric.ed.gov/ fulltext/EJ919871.pdf

Ghasemi, A, \& Zahediasl, S. (2012). Normality test for statistical analysis: guide for non-statisticians. International Journal of Endocrinology and Metabolism, 10 (2), 486489. DOI: 10.5812/ijem.3505

Gichuki, J, Njeru, A, \& Tirimba, O. (2014). Challenges Facing Micro and Small 
Enterprises in Accessing Credit Facilities in Kangemi Harambee Market in Nairobi City County, Kenya. International Journal of Scientific and Research Publications, 4 (12), 1-25. Retrieved from http://www.ijsrp.org/ research-paper-1214/ijsrp-p3614.pdf

Jayadatta, Y. (2017). Major challenges and problems of rural entrepreneurship in India. IOSR Journal of Business and Management, 19 (9), 35-44. Retrieved from http://www. iosrjournals.org/iosr-jbm/papers/Vol19issue9/Version-2/D1909023544.pdf

Louanglath, P.I. (2017). Minimum sample size method based on survey scales. International Journal of Research and Methodology in Social Science, 3 (3), 45. DOI: 10.5281/zenodo.1322593

Lund Research Ltd. (2018). Testing for normality using SPSS statistics. Retrieved from https:// statistics.laerd.com/spss-tutorials/testingfor-normality-using-spss-statistics.php

Mangalam, R. (2019). Farmers' attitude towards kisan credit card scheme in Tamil Nadu - A study with reference to Madurai district. Unpublished PhD dissertation, Madurai Kamaraj University, Tamil Nadu, India. Retrieved from https://tcarts.in/research/ research/phd_synopsis_mang.pdf

Nath, D., Jain, P.K., Talukdar, R.K., \& Hansra, B.S. (2016). Constraints Encountered by the Beneficiaries of Krishi Vigyan Kendra in North Eastern Region of India. Journal of Extension Education, 28 (2), 5665 -5668. https://doi.org/10.26725/ JEE.2016.2.28.5665-5668
Shanmugavadivel, D. (2015). A study on awareness of farmers in agricultural finance in public sector banks with special reference to Coimbatore district. International Journal of Science and Research, 6 (6), 2636-2638.

Sharma, D. (2012). Problems and prospects of the agricultural sector in Assam- A case study of Sonitpur district. Retrieved from http://www.nagalanduniv.ndl.iitkgp. ac.in/bitstream/handle/1/30/T00020. pdf? sequence $=1$ \&isAllowed $=y$

Subramaniam, R \& Shivananjappa, S. (2017). Investigation on the problems faced by the farmers in obtaining and repayment of agricultural credit in Karaikal district, India. International Journal of Current Microbiology and Applied Sciences, 6 (6), 3966-3971. https://doi.org/10.20546/ ijcmas.2017.611.463

Swathy, S \& Benazir, Y. (2014). A study on the challenges faced by entrepreneurs. Intercontinental Journal of Marketing Research Review, 2(4), 18-28.

Thakur, A \& Barman, U. (2013). Reasons for poor performance of disbursement of Kishan Credit Card and recovery of loan under the scheme in Assam - a qualitative study. Journal of Academia and Industrial Research, 2 (1), 16-20.

Ulusoy, T\& Celik, M.Y. (2019). Financial literacy in the agricultural products industry: the case of Kastamonu. Alinteri Journal of Agricultural Sciences, 34 (1), 57-66.

Widhiyanto, I, Nuryartono, N, Harianto., \& Siregar, H. (2018). The analysis of 
Influence of Agricultural Financing Awareness on Financial Problems of Agricultural Entrepreneurs

farmers' financial literacy and its' impact on microcredit accessibility with interest subsidy on the agricultural sector. International Journal of Economics and Financial Issues, 8 (3), 148-159.
Yadav, H. (2013). Agricultural marketing system in Assam. National Institute of Agricultural Marketing. Retrieved from https://www. ccsniam.gov.in/images/pdfs/Assam _ Research_report.pdf 